\section{MAKING STUFF premieres in January on PBS}

\author{
www.mrs.org/makingstuff \\ www.pbs.org/nova/makingstuff
}

\begin{abstract}
Watch MAKING STUFF with David Pogue on your local PBS station. This is a four-part series exploring the materials that will shape the future. Premieres January 19, 2011 at 9:00 pm ET/PT (check local listings)
\end{abstract}

$\mathbf{W}$ hat is the strongest material in the world? Is it iron? Are Kevlar and carbon nanotubes the way of the future, or will the powerful properties discovered in natural spider silk one day replace steel? From the Stone Age, Bronze Age, and Iron Age to more recent periods dominated by plastics and silicon, materials have defined the progression of humankind. Now, we are once again poised on the verge of a materials revolution, as researchers around the globe push the boundaries further than ever before, using biology and chemistry to imbue materials with new qualities that are expanding our technological frontiers.

In NOVA's new four-hour series, MAKING STUFF, popular New York Times technology reporter David Pogue takes viewers on a thrilling tour of the materials world we live in, and the one that may lie ahead - offering viewers a behind-the-scenes look at scientific innovations that are ushering in a new generation of materials that are stronger, smaller, cleaner, and smarter, than anything we have ever seen.

NOVA begins the ambitious fourhour program with a quest for the world's strongest stuff. Host David Pogue helps viewers understand what defines strength. Pogue explores the world of high-strength steel on aircraft carriers and how we study the failure mechanisms using high-speed photography. He examines the accidental discovery of Kevlar and its subsequent use in fabrics and explores the next generation of stronger materials including the use of genetic engineering to produce artificial spider silk. Pogue even explores the world of biomimetics for stronger materials focusing on examples ranging from polymeric-based composites that mimic toucan beaks to ceramic-based composites that mimic abalone shell. The goal is to show how nature may provide us with answers for the next generation of strong "stuff."

How small can we go? Could we one day have robots taking "fantastic voyages" in our bodies to kill rogue cells? In the MAKING STUFF: Smaller program, Progue takes viewers into the world of microscopic materials. He explores the historical challenges of making materials small from watches to the integrated circuit. He examines how the planar technology of silicon may evolve into nonplanar devices based on nanowires of silicon or how the silicon itself may be replaced by two-dimensional carbon. Pogue then examines how the decrease in device size has enabled advances in medical science such as in situ cameras that can be swallowed. He then ventures into the field of controlling drug delivery through magnetic fields or flagella. Pogue even explores how the nanotechnology to come from controlling particle morphology at the atomic scale could change the face of medicine, from novel diagnosis to targeting.

Many modern materials are dangerous to the environment, but what about cleaning up our world? In MAKING STUFF: Cleaner, Pogue explores the rapidly developing science and business of clean energy and examines alternative ways to generate it, store it, and distribute it. Concepts such as making carbon nanotubes from plastic bags to making clothing from sugar are explored. Pogue examines alternative green sources of hydrocarbons for polymers from clothing made from sugar to rubber made from orange peels. Novel methods of producing and storing energy from photovoltaics for hydrogen production to batteries grown from viruses - these are just a few glimpses of a new generation of clean materials that could power devices of the future. Pogue investigates the latest developments in biobased fuels and in harnessing solar energy for our cars, homes, and industry in a fascinating hour full of the "stuff" of a sustainable future.

There is a novel class of materials that responds to external stimuli. In the "smarter" episode, Pogue explores how nature can be used to help inspire scientists to develop materials that can both mimic natural responses and potentially change when externally stimulated. Pogue shows how mimicking the skin of a shark has led to the first structural antibiotic or how mimicking the bonding found in Gecko feet can

MRS

be used to facilitate robot transportation. "Smarter" looks into the growing number of materials that almost seem alive - able to react and change dynamically - from an army tanker truck that heals its own bullet wounds to an airplane wing that relies on piezoelectric ceramics to change shape as it flies. Pogue finds out how non-Newtonian fluids can improve shock absorbers and how so-called metamaterials may lead to a revolution in the manipulation of light. For inspiration and ideas, scientists are turning to nature and biology and producing some innovative new developments in materials science.

MAKING STUFF: Stronger, Smaller Cleaner, Smarter is a four-part PBS prime-time television series from the award-winning producers of NOVA, developed in partnership with the Materials Research Society. The first episode, MAKING STUFF: Stronger, is slated to air on Wednesday January 19, 2011 and then followed by the other episodes on three consecutive weeks of viewing.

Kevin Jones

University of Florida, Gainesville and MRS Public Outreach Committee Jennifer Larese WGBH Education Outreach Department 